\title{
Carboxylate derivatives of tributyltin (IV) complexes as anticancer and antileishmanial agents
}

\author{
Durdana Waseem', Arshad Farooq Butt', Ihsan-ul Haq ${ }^{1}$, Moazzam Hussain Bhatti ${ }^{2}$ and Gul Majid Khan ${ }^{1 *}$
}

\begin{abstract}
Background: Tributyltin (IV) compounds are promising candidates for drug development. In the current study, we evaluated in-vitro and in-silico profile of carboxylate derivatives of tributyltin (IV) complexes.

Methods: ADMET and drug-likeliness properties were predicted using MetaPrint2D React, preADMET, SwissADME and Molsoft tools. SwissTargetPrediction predicted molecular targets for compounds. In-vitro bioactivity was evaluated by quantifying cytotoxicity against HepG2, THP-1 cell lines, isolated lymphocytes and leishmania promastigotes as well as measuring protein kinase (PK) inhibition activity.

Results: Results indicate partial compliance of compounds with drug-likeliness rules. Ch-409 complies with WDI and Lipinski rules. ADMET profile prediction shows strong plasma protein binding except for $\mathrm{Ch}-409$, low to high Gl absorption and BBB penetration $\left(C_{\text {brain }} / C_{\text {blood }}=0.942-11\right.$; caco- 2 cells permeability $\left.20.13-26.75 \mathrm{~nm} / \mathrm{sec}\right)$, potential efflux by P-glycoprotein, metabolism by CYP3A4, medium inhibition of hERG, mutagenicity and capacity to be detoxified by glutathionation and glucuronidation. Molecular targets include proteases, enzymes, membrane receptors, transporters and ion channels where Ch-409 targets membrane receptors only. Compounds are significantly $(p<0.05)$ cytotoxic against HepG2 cell line and leishmania as compared with normal isolated lymphocytes. Ch-459 indicates highest toxicity against leishmania (mortality $97.9 \pm 3.99 \%$; LC50 $0.323 \pm 0.002 \mu \mathrm{g} / \mathrm{mL}$ ) whereas Ch-409 possesses maximum cytotoxicity against HepG2 cell line (IC50 $0.08 \pm 0.001 \mu \mathrm{g} / \mathrm{mL}$ ) as well as 97.5 $\pm 1.98 \%$ (LC50 $0.954 \pm 0.158 \mathrm{\mu g} / \mathrm{mL}$ ) mortality of leishmania promastigotes. It was observed that antileishmanial effect was reduced by $16.38 \%-34.38 \%$ and $15-38.2 \%$ in the presence of $\mathrm{NaN}_{3}$ and mannitol respectively. PK inhibition and reactive oxygen species production are possible mechanisms for cytotoxicity.

Conclusions: Selected carboxylate derivatives of tributyltin (IV) complexes possess significant antileishmanial and cytotoxic potential. These are promising compounds for the development of antileishmanial and anticancer drugs.
\end{abstract}

Keywords: Organotin (IV), Anticancer, Antileishmanial, ADMET, Protein kinase inhibition

\section{Background}

Cancer and leishmaniasis are major threats to humans causing significant morbidity and mortality worldwide. Leishmaniasis is caused by transmission of leishmania parasite through sand fly in both endemic and nonendemic areas [1]. Lack of effective measures to control both parasite and sand fly are major factors for the spread of disease. Current therapies are inadequate to

\footnotetext{
* Correspondence: gmkhan@qau.edu.pk

'Department of Pharmacy, Quaid-i-Azam University, Islamabad 45320,

Pakistan

Full list of author information is available at the end of the article
}

manage cancer and leishmaniasis due to diversity of molecular disruptions and development of resistance respectively. Cancer evolves by deregulating endogenous functions of molecular proteins, which in turn can be targeted to impede cancer progression. Anticancer drugs are developed and investigated against angiogenesis, extracellular matrix proteins and a variety of signal transduction pathways, including mitogen-activated protein kinase (MAPK), Janus-activated kinase, transforming growth factor-beta, p53, Ras, Wnt and Akt signaling [2, 3]. Treatment strategies against leishmaniasis involve killing parasite by DNA fragmentation, formatting aqueous pores 
in promastigotes cell membrane, oxidative mitochondrial damage, decreasing mitochondrial membrane potential, affecting peptidases that constitute leishmania genome and disrupting kinases responsible for leishmania division and differentiation [4]. Glycogen synthase kinase that control leishmania cell cycle, is a new potential target for antileishmanial drugs [5].

Regression of cancer and leishmaniasis is a challenge that can be accomplished by developing efficacious and cost-effective drugs. Among multiple synthetic drugs, organometallic compounds are prospective candidates for anticancer and antileishmanial drug discovery [6, 7]. Organometallics including pentavalent antimonials [8] and platin derivatives [9] have been used for over three decades for the management of leishmaniasis and cancer respectively [10]. Sodium stibogluconate and meglumine antimoniate are first line drugs against all forms of leishmaniasis [11]. On the other hand, carboplatin, oxaliplatin and cisplatin are commonly employed metal based drugs against ovarian, breast, head/neck, bladder, lung and colorectal cancers [12]. Efficacy of these compounds is compromised due to substantial risk of toxicities and emergence of resistance $[8,12]$. Clinical limitations and inadequate control of subject diseases demand to investigate new drugs. It is general consensus that there are other metals in periodic table with therapeutic potential. Structural diversity and redox and catalytic properties of organometallics make them promising drug candidates. Among these, organotin (IV) compounds have caught the attention of researchers for their prospective biocidal activities. Carboxylate derivatives of organotin (IV) compounds have been previously investigated for their anticancer and antileishmanial profile [10]. Novel tin based compounds have been characterized with proven antibacterial, antifungal and antitumor activities [13, 14]. Considering the growing importance of organotin (IV) compounds in medicine, the present study was designed to evaluate the cytotoxic potential of tributyltin (IV) compounds against cancer cells and leishmania. The rationale was to appraise metal based drugs that can be effective and efficacious in managing rapidly spreading cancers and leishmaniasis. We assessed in-silico druglikeliness, ADMET profile and in-vitro anticancer and antileishmanial activities of new carboxylate derivatives of tributyltin (IV) ligand.

\section{Methods}

\section{Chemicals, cell lines and strains}

Standards including surfactin, amphotericin B and vincristine were procured from Sigma-Aldrich (Steinheim, Germany). Doxorubicin was purchased from Merck (Darmstadt, Germany). Medium ISP4 for protein kinase (PK) assay was prepared in the laboratory. Unless stated otherwise, all other chemicals were purchased from
Sigma-Aldrich (Germany). Human leukemia (THP-1) (ATCC \# TIB-202) and human hepatoma (HepG2) (RBRC-RCB1648) cell lines were used for cytotoxicity assays. Streptomyces 85E and Leishmania tropica kwh 23 were used for protein kinase inhibition and antileishmanial assays respectively.

\section{Compounds}

Carboxylate derivatives of tributyltin (IV) backbone were selected from library of synthetic compounds present at our laboratory (Fig. 1). These compounds were selected based on structural similarity to compounds previously reported to possess cytotoxic profile [10]. These included bis(tributylstannyl) 2,2'-(1,4-phenylenebis(oxy))diacetate (Ch-409), ethyl (Z)-4-(4-oxo-4-((tributylstann yl)oxy)but-2-enamido)benzoate (Ch-431), tributylstannyl (Z)-4-(cyclohexylamino)-4-oxobut-2-enoate (Ch-442), tributylstannyl 4-(4-oxo-4-((tributylstannyl)oxy)butanam ido)benzoate (Ch-448), tributylstannyl 2-(naphthalene-1ylcarbamoyl)benzoate (Ch-450), tributylstannyl (Z)4-oxo-4-(phenylamino)but-2-enoate (Ch-458) and tribut ylstannyl (Z)-4-((2,3-dimethylphenyl)amino)-4-oxobut2-enoate (Ch-459). Synthesis and characterization data on these compounds are submitted for publication elsewhere.

\section{In-silico screening \\ Drug-likeliness prediction}

PreADMET and Molsoft tools were utilized to determine the drug-likeliness of tributyltin (IV) compounds and some marketed drugs [15]. PreADMET calculates druglikeliness of compounds based on Lipinski rule, lead-like rule, CMC-like rule, MDDR-like rules and World Drug Index (WDI) rule. 2D structural models were drawn in ChemBioDraw Ultra version 12.0 (Cambridge Software) and SMILES of each compound were translated into molfile by online SMILES translator and structure file generator (National Cancer Institute) [16]. Molfile data was added into the database to predict drug-likeliness properties. Drug-likeliness score was calculated from Molsoft using SMILES as input.

\section{ADMET profile prediction}

ADMET profile of tributyltin (IV) compounds was predicted using PreADMET and SwissADME tools [17]. Molfiles created for each compound were added into the database and searched for ADMET properties. Degree of plasma protein binding (PPB) is categorized in preADMET as strongly bound if $\% \mathrm{PPB}>90 \%$ and weakly bound if $\% \mathrm{PPB}<90 \%$. Blood brain barrier (BBB) penetration is presented as concentration ratio of steady-state of radiolabeled compounds in brain $\left(\mathrm{C}_{\text {brain }}\right)$ and peripheral blood $\left(\mathrm{C}_{\text {blood }}\right)$. Compounds are classified into high, middle and low absorbing into CNS with 


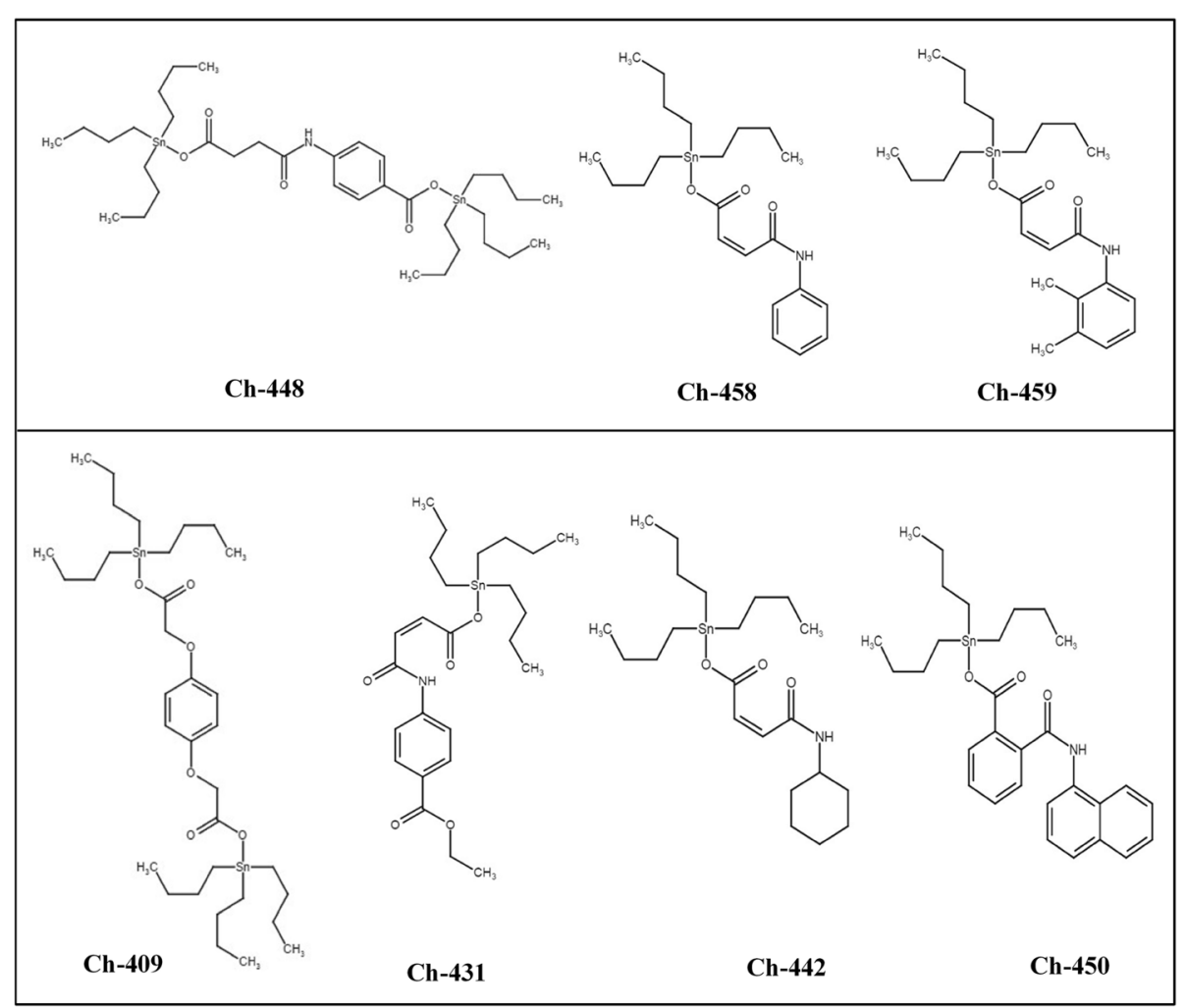

Fig. 1 Structures of tributyltin (IV) compounds

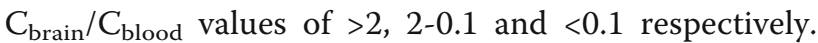
For assessing intestinal absorption, Caco-2 cell model categorizes compounds as low, middle and highly permeable corresponding to values $<4 \mathrm{~nm} / \mathrm{sec}, 4-70 \mathrm{~nm} /$ $\mathrm{sec}$ and $>70 \mathrm{~nm} / \mathrm{sec}$ respectively. SwissADME predicts $\mathrm{BBB}$ penetration and GI absorption by BOILED-Egg method [18]. It also classified compounds as targets of p-glycoprotein (p-gp) efflux, inhibitors of cytochrome P450 enzymes CYP2C9, CYP2C19, CYP2D6 and CYP3A4 and substrates for metabolism by CYP2D6 and CYP3A4. PreADMET anticipated toxicity of compound on models of Ames test with or without metabolic activation by S9 (rat liver homogenate) against strains of Salmonella typhimurium TA100 and TA1535 and rodent carcinogenicity constructed on National Toxicology Program and FDA US data on in-vivo 2 year carcinogenicity tests of mice and rats. Results are produced are positive or negative mutagenicity or carcinogenicity.

Metabolism of compounds via phase I and phase II reactions was predicted using MetaPrint2D React [19, 20] subjected to similarity to known sites of metabolism. It calculates normalized occurrence ration (NOR) indicating relative likelihood of metabolism, which occurs at a specific site in the molecule.

\section{Molecular target prediction}

Molecular targets were predicted by SwissTargetPrediction online tool [21]. Query molecules were drawn in $2 \mathrm{D}$ using the javascript-based molecular editor of ChemAxon and submitted to the database. SwissTargetPrediction envisages molecular targets based on chemical similarity (2D) and/or structural similarity (3D) among bioactive molecules. A threshold for 3D and 2D similarity values has been set to 0.75 and 0.45 respectively. Compounds having values beyond these thresholds are not listed.

\section{In-vitro screening \\ Cytotoxicity against THP-1 cell line}

Cytotoxicity of tributyltin (IV) compounds against THP1 cell line was determined by 3-(4,5-dimethylthiazol-2yl)-2,5-diphenyl tetrazolium bromide (MTT) assay [22]. THP-1 cells were cultured in complete growth medium comprising RPMI-1640 (pH 7.4) supplemented with $2.2 \mathrm{~g} / \mathrm{L} \mathrm{NaHCO}_{3}$ and $10 \% \mathrm{v} / \mathrm{v}$ heat inactivated fetal bovine serum (HIFBS). An aliquot of $20 \mu \mathrm{L}$ of samples in $1 \% \mathrm{DMSO}$ in PBS and $180 \mu \mathrm{L}$ of THP-1 cells were mixed in 96-well plate. Cells were added at an assay density of $1 \times 10^{4}$ cells $/ \mathrm{mL}$ whereas sample/standard was added to achieve the final concentration of $20 \mu \mathrm{g} / \mathrm{mL}$. 
The plate was incubated at $37{ }^{\circ} \mathrm{C}$ for $72 \mathrm{~h}$ in humidified $5 \%$ carbon dioxide incubator (Panasonic, Japan MCO18 AC-PE). Vincristine and 1\% DMSO in PBS were used as positive and negative controls respectively. After incubation, $20 \mu \mathrm{L}$ of pre-filter sterilized MTT solution ( $4 \mathrm{mg} / \mathrm{mL}$ in distilled water) was added in plates and incubated for $4 \mathrm{~h}$ at $37{ }^{\circ} \mathrm{C}$ in $\mathrm{CO}_{2}$ incubator. Later, colored formazan crystals were separated by removing supernatant and dissolved in $100 \mu \mathrm{L}$ of DMSO. Reaction was allowed to stand for $1 \mathrm{~h}$ to ensure complete dissolution and absorbance was measured at $540 \mathrm{~nm}$ using microplate reader (Biotech USA, Elx 800).

\section{Cytotoxicity assays against HepG2 cell line}

Cytotoxicity was further evaluated against HepG2 cell line by sulforhodamine B (SRB) colorimetric assay [22]. Dulbecco's Modified Eagle Medium (DMEM) supplemented with $10 \% \mathrm{FBS}, 100 \mu \mathrm{g} / \mathrm{mL}$ streptomycin sulfate, $100 \mathrm{IU} / \mathrm{mL}$ penicillin G sodium and $0.25 \mu \mathrm{g} / \mathrm{mL}$ amphotericin $\mathrm{B}$ was used to culture HepG2 cells in $\mathrm{CO}_{2}(5 \%)$ incubator (Panasonic, Japan MCO-18 AC-PE) at $37{ }^{\circ} \mathrm{C}$. An aliquot of $20 \mu \mathrm{L}$ (1\% DMSO in PBS) of samples was added to $180 \mu \mathrm{L}$ of cell culture at an assay density of $1 \times 10^{5}$ cells $/ \mathrm{mL}$ in 96 -well plate. The plate was incubated at $37{ }^{\circ} \mathrm{C}$ for $72 \mathrm{~h}$ in $\mathrm{CO}_{2}$ incubator. Final concentration of compounds/standard was $20 \mu \mathrm{g} / \mathrm{mL}$. Doxorubicin and $1 \% \mathrm{v} / \mathrm{v}$ DMSO in PBS ere used as positive and negative controls respectively. An equivalent number of cells in twelve wells of 96-well plate were incubated for $1 \mathrm{~h}$ at $37{ }^{\circ} \mathrm{C}$ and labeled as day zero control. Later, cells were fixed by adding $50 \mu \mathrm{L}$ of cold $20 \% \mathrm{w} / \mathrm{v}$ TCA for $1 \mathrm{~h}$ at $4{ }^{\circ} \mathrm{C}$. These were washed with tap water, air dried and stained with $50 \mu \mathrm{L}$ of $0.057 \% \mathrm{w} / \mathrm{v}$ SRB in $1 \% \mathrm{v} / \mathrm{v}$ acetic acid for $30 \mathrm{~min}$ at room temperature. Cells were again washed with $1 \% \mathrm{v} / \mathrm{v}$ acetic acid, dried overnight and $200 \mu \mathrm{L}$ of $10 \mathrm{mM}$ Tris base $(\mathrm{pH} 10)$ was used to solubilize the bound dye for $1 \mathrm{~h}$. Absorbance was measured at $515 \mathrm{~nm}$ using a microplate reader. Percentage of growth inhibition was calculated as: \% inhibition $=100-\left[\left(A_{s}-A_{o}\right) /\left(A_{n}-A_{o}\right) \times 100\right]$, where, $A_{o}$, $A_{s}$ and $A_{n}$ are absorbance of day zero control, samples and negative control respectively. IC50 values were determined using 3-fold dilutions of the samples.

\section{Cytotoxicity against isolated lymphocytes}

Lymphocytes were isolated using previously described protocol with some modifications [23, 24]. Informed consent was obtained from volunteers and procedure was conducted according to international ethical guidelines after gaining approval from the ethical committee of the Quaid-i-Azam University. A volume of $3 \mathrm{~mL}$ of blood was obtained from a healthy donor by venipuncture and diluted (1:1) with PBS. It was layered over $2 \mathrm{~mL}$ Histopaque-1077 and centrifuged at $800 \times \mathrm{g}$ for $20 \mathrm{~min}$. The buffy coat was aspirated into $5 \mathrm{~mL}$ of PBS and centrifuged at $350 \mathrm{rpm}$ for 4 min to pellet the lymphocytes. The pellet was suspended in $1 \mathrm{~mL}$ of RPMI-1640 and cell density was adjusted to get $1 \times 10^{5}$ cells $/ \mathrm{mL}$. For cytotoxicity determination, $20 \mu \mathrm{L}$ of samples $(20 \mu \mathrm{g} / \mathrm{mL})$ or vincristine or $1 \%$ DMSO in PBS and $180 \mu \mathrm{L}$ of lymphocyte suspension were incubated in 96-well plate at $37^{\circ} \mathrm{C}$ for $24 \mathrm{~h}$ in humidified $5 \%$ carbon dioxide incubator (Panasonic, Japan MCO-18 AC-PE). Phytohaemagglutinin (PHA) was added in medium to stimulate lymphocyte growth. Afterwards, MTT assay was done as described above. IC50 values were determined using 3-fold dilutions of the samples.

\section{Antileishmanial activity}

Antileishmanial activity against the promastigotes of Leishmania tropica kwh 23 was evaluated by a quantitative colorimetric assay using 3-(4,5-dimethylthiazol-2yl)-2, 5-diphenyl tetrazolium bromide (MTT) with minor modifications [25, 26]. Leishmania tropica parasites were cultured in Medium 199 supplemented with $10 \% \mathrm{FBS}, 100 \mu \mathrm{g} / \mathrm{mL}$ streptomycin sulfate and $100 \mathrm{IU} /$ $\mathrm{mL}$ penicillin $\mathrm{G}$ at $24{ }^{\circ} \mathrm{C}$. A volume of $20 \mu \mathrm{L}$ of extracts $(100 \mu \mathrm{g} / \mathrm{mL} ; \mathrm{DMSO} \leq 1 \%$ in PBS $)$ and amphotericin B $(0.33-0.004 \mu \mathrm{g} / \mathrm{mL})$ were incubated with $180 \mu \mathrm{L}$ of promastigotes at seeding density $2 \times 10^{6}$ cells $/ \mathrm{mL}$ in 96 -well flat bottom plate at $25{ }^{\circ} \mathrm{C}$ for $72 \mathrm{~h}$. Negative control wells contained $1 \%$ DMSO in PBS. All samples were run in triplicate. Afterwards, plates were incubated for $4 \mathrm{~h}$ at $24{ }^{\circ} \mathrm{C}$ with $20 \mu \mathrm{L}$ of MTT $(4 \mathrm{mg} / \mathrm{mL}$ in distilled water) to determine the cell viability. Supernatant from each well was carefully removed leaving behind formazan crystals. Colored formazan crystals were dissolved in $100 \mu \mathrm{L}$ of DMSO by setting those aside for $1 \mathrm{~h}$ to ensure complete dissolution. Cell viability was estimated by measuring absorbance at $540 \mathrm{~nm}$ using microplate reader and percentage growth inhibition was calculated.

\section{Determining photosensitizing effect against leishmania}

Photosensitizing effect of tributyltin (IV) compounds was determined in three parallel groups [27]. Samples and controls were exposed for $15 \mathrm{~min}$ to sunlight $\left(168 \mathrm{~W} / \mathrm{m}^{2}\right.$ of sun intensity) or sunlight with IR filter or dark conditions. The relative intensity of sunlight was measured by a CCD spectrometer (Ocean Optics, model HR4000). Later, plates were incubated at $25^{\circ} \mathrm{C}$ for $72 \mathrm{~h}$ and cell viability was determined by MTT assay as given above. In this assay, samples were tested at concentrations showing less than 55\% inhibition in primary antileishmanial assay to exclude false positive.

\section{Determining ROS mediated antileishmanial activity}

Leishmania tropica kwh 23 promastigotes were treated in three groups [27]. First group was exposed to samples 
along with $0.1 \mathrm{mM}$ sodium azide $\left(\mathrm{NaN}_{3}\right)$, second group to samples with $1 \mathrm{mM}$ mannitol and third group comprised of all controls. In third group, promastigotes were treated in different wells with samples only (sample control), 1\% DMSO in PBS only (negative control-I), amphotericin B only (positive control), $0.1 \mathrm{mM} \mathrm{NaN}_{3}$ only (negative control-II) and $1 \mathrm{mM}$ mannitol only (negative control-III). Plates were incubated followed by MTT assay described above.

\section{Protein kinase inhibition assay}

Protein kinase inhibitory activity of the tributyltin (IV) compounds was measured against Streptomyces 85E strain using previously described protocol [28]. Culture of Streptomyces 85E was refreshed in tryptic soy broth and $100 \mu \mathrm{L}$ of this was swabbed on sterile ISP4 medium under aseptic conditions. Sterile filter paper discs $(6 \mathrm{~mm})$ impregnated with $5 \mu \mathrm{L}$ of samples $(10 \mathrm{mg} / \mathrm{mL}$ in DMSO) or surfactin (2 $\mathrm{mg} / \mathrm{mL}$ in DMSO; positive control) or DMSO (negative control) were placed on Streptomyces swabbed petri plate and incubated for $72-96 \mathrm{~h}$ at $30{ }^{\circ} \mathrm{C}$. Diameter $(\mathrm{mm})$ of zone of inhibition (ZOI) around all samples and controls was measured as clear zone (CZ) and bald zone (BZ). Clear zone represents Streptomyces growth inhibition whereas bald zone shows inhibition of hyphae and spore formation. BZ is indicative of PK inhibition.

\section{Statistical analysis}

Data is presented as Mean \pm SD of respective parameters in triplicate analysis. One Way Analysis of Variance (ANOVA) was applied to measure significance of results. $\mathrm{p}<0.05$ was considered statistically significant. Analysis was done using GraphPad Prism 5.0 software.

\section{Results and discussion}

\section{Drug-likeliness prediction}

Drug-likeliness prediction is important to optimize pharmaceutical and pharmacokinetic properties of compounds [29]. Tributyltin (IV) carboxylate compounds partially comply with selected rules of drug-likeliness. Ch- 409 was in $90 \%$ cutoff range of WDI rule and complies with all conditions of Lipinski rule. Ch-458, 431, 448,459 and 442 are mid-structures whereas Ch-450 is drug-like according to MDDR-like rule (Fig. 2). In practice, we have drugs in market that do not completely comply with drug-likeliness rules but are used due to their high beneficial effects for humans to treat cancer. For example, vincristine, which violates CMC-like, leadlike and Lipinski rules and complies with MDDR-like rule. Besides, cisplatin does not completely comply with any of the above rules. Drug-likeliness scores computed from Molsoft tool also indicate these compounds as moderately drug-like. Higher the score, greater the druglikeliness conforming to available drugs [30]. Tributyltin (IV) compounds scores are $-1.11,0.42,-0.23,0.15,0.40$,0.49 and 0.27 for Ch-409, Ch-431, Ch-442, Ch-448, Ch-450, Ch-458 and Ch-459 respectively. On the other hand, cisplatin, vincristine, doxorubicin, amphotericin B, dactinomycin and sorafenib have drug-likeliness scores of $-1.12,1.38,1.02,0.9,-1.00$ and 0.51 respectively. Thus, our compounds have comparable drug-likeliness profile with marketed drugs and are good drug candidates.

\section{ADMET prediction}

ADME analysis done by PreADMET predicts that tributyltin (IV) carboxylate compounds have middle to high BBB permeability based on $C_{\text {brain }} / C_{\text {blood }}$ ratio of $0.942-$ 11 whereas SwissADME predicts no BBB crossing since these compounds are also substrates for p-glycoprotein efflux (Table 1). P-gp is present on the apical surface of endothelial cells of blood brain barrier and impedes the entry of various drugs [31]. All compounds strongly bind with plasma protein except Ch-409 and have low to high GI absorption (caco-2 cells permeability 20.13$26.75 \mathrm{~nm} / \mathrm{sec}$ ). These compounds can be formulated into oral dosage form. Ch-409 is inhibitor of CYP2C19; Ch-450 and Ch-409 are inhibitors of CYP2C9; Ch-458, Ch-431, Ch-450, Ch-448, Ch-459 and Ch-442 are of CYP2D6 and Ch-450, Ch-409 and Ch-448 inhibit

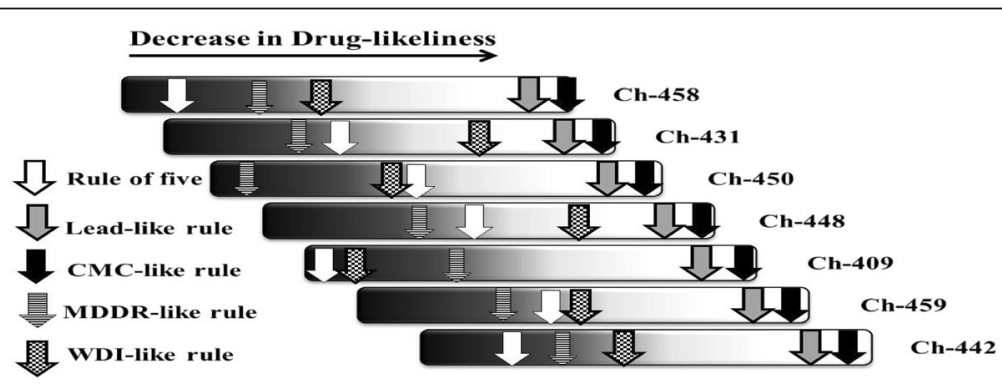

Fig. 2 Drug-likeliness profile of tributyltin (IV) compounds: The color from black to white indicates decrease in compliance with drug-likeliness rules. Placement of arrows on compliance bar shows the extent to which a compound conform to respective rule depending upon number of the conditions fulfilled for each rule. It is predicted from PreADMET 


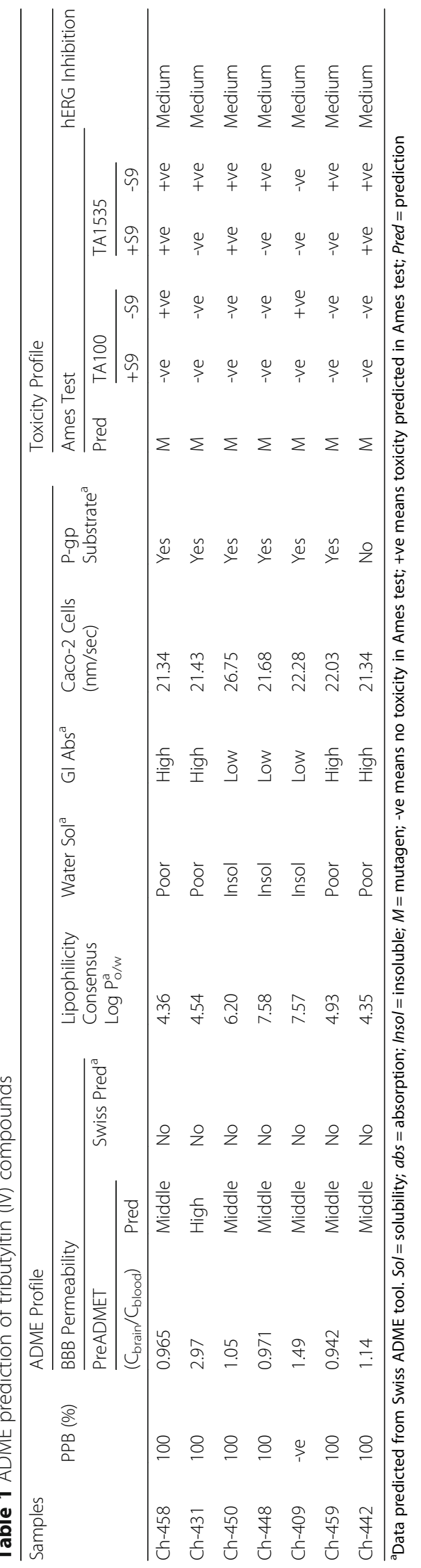


CYP3A4. No compound is substrate of CYP2D6 whereas all others except Ch-409, Ch-458 and Ch-442 are strong substrates for metabolism by CYP3A4. Our compounds were found mutagenic in Ames test either by point or frame-shift mutations (Table 1). Metabolic activation predicts mutagenicity of metabolites of Ch- 458 , Ch- 450 and Ch-442. Carcinogenicity prediction was "out of range" in the database expect for Ch-409, which was not carcinogenic in rat model. Human ether a go-go-related (hERG) gene encodes cardiac potassium channels that mediate repolarization phase. Inhibition of these prolong QTc interval along with the risk of cardiac arrhythmias [32]. Our compounds show medium risk of hERG inhibition. Since, compounds show very high $\mathrm{PPB}$ and very low IC/LC50 values in in-vitro analysis; therefore, it is necessary to assess the concentration at which hERG inhibition risk is predominant.

Metabolic sites predicted by MetaPrint2D React are highlighted as red $(0.66 \leq \mathrm{NOR} \leq 1.00)$, orange $(0.33 \leq$ NOR $<0.66)$, green $(0.15 \leq \mathrm{NOR}<0.33)$, white $(0.00 \leq$ NOR $<0.15$ ) and grey (little/no data) corresponding to NOR where high NOR means most frequently reported site in metabolism database (Fig. 3). It was found that besides dealkylation, hydroxylation and oxidation, all compounds are possibly metabolized by multiple phase I and phase II reactions. Ch-409 can undergo acetylcysteination and glutathionation; Ch-431 is metabolized by demethylation and glucuronidation; $\mathrm{Ch}-448$ by glucuronidation; Ch-450 go through epoxidation, glutathionation, sulfonation, oxidative deamination and methoxylation whereas

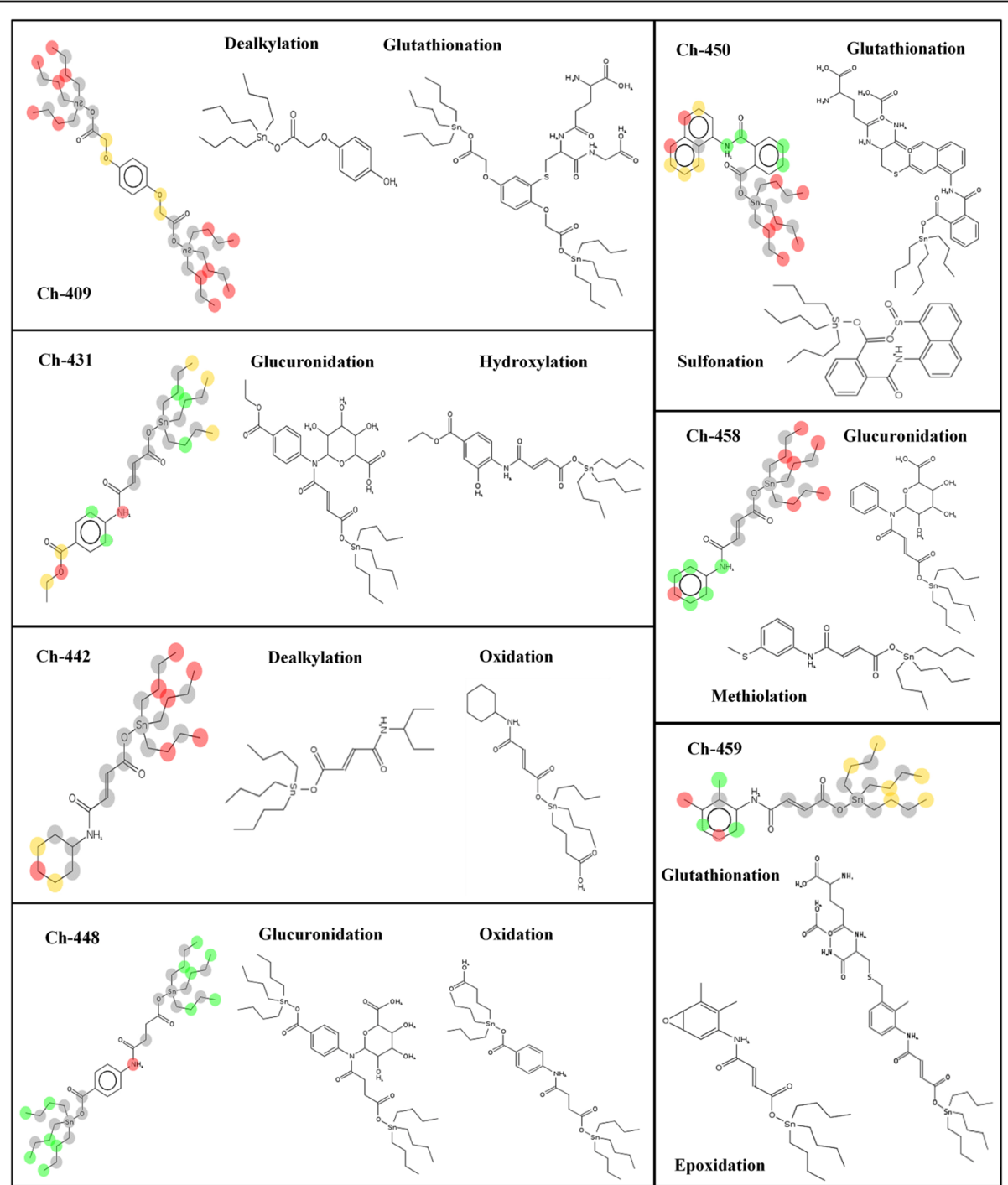

Fig. 3 Predicted metabolic sites and metabolites of tributyltin (IV) compounds. Structures with colored circles indicate the metabolic sites predicted by MetaPrint2D React. Color codes are given based on normalized occurrence ratio. Red $=0.66 \leq \mathrm{NOR} \leq 1.00$; orange $=0.33 \leq \mathrm{NOR}<0.66$; green $=0.15 \leq$ $\mathrm{NOR}<0.33$; white $=0.00 \leq \mathrm{NOR}<0.15$ and grey $=$ little/no data. Two possible metabolites for each compound are given with NOR $\geq 0.33$ 
epoxidation, glucuronidation, methiolation, methoxylation are predicted for Ch-458 and epoxidation, glutathionation and methoxylation for Ch-459 (Fig. 3). Glucuronidation and glutathione metabolism of compounds make these hydrophilic and ionized at physiological $\mathrm{pH}$. This also reduces their affinity with cellular target [33]. It is proposed that metabolism at multiple sites will excrete the compounds out of the body with less side effects of metabolites.

\section{Molecular target prediction}

Molecular target prediction by SwissTargetPrediction tool provided possible interaction sites for tributyltin (IV) compounds. These include proteases, enzymes, transcription factor, receptors, ion channels and other proteins (Fig. 4). Although the probabilities of interaction with targets was low (range: 0.01-0.1) based on ChEMBL database; however, in-vitro analysis depicts good bioactivity profile of these compounds. This means that they interact strongly with cellular proteins and modify their functions to kill cancer cells and leishmania parasite. It was predicted that Ch-409 can bind with membrane receptors such as opioid (mu, kappa, delta) and nociceptin receptors. On the contrary, Ch-431 dominantly aims enzymes (47\%) acetylcholinesterase, inosine-5'-monophosphate dehydrogenase 2 and tyrosyl-DNA phosphodiesterase 1; transcription factor (7\%) hypoxia-inducible factor 1-alpha and other proteins (33\%) including microtubuleassociated protein tau and muscleblind-like protein 1, 2 and 3. Ch-442 was predicted to interact with serine proteases (60\%) cathepsin G, granzyme $B$ and $H$, chymotrypsin- $\mathrm{C}$ and chymotrypsin-like elastase family member $2 \mathrm{~A}$ and enzymes (40\%) peptidyl-prolyl cis-trans isomerase FKBP1A and $\mathrm{B}$ and peptidyl-prolyl cis-trans isomerase $\mathrm{FKBP} 4$ and 5. Ch-448 can regulate transporters (47\%), for examples, excitatory amino acid transporters 1, 2, 3, 4 and 5. Other proteins include tyrosyl-DNA phosphodiesterase 1, FAD-linked sulfhydryl oxidase ALR; muscleblind-like proteins and membrane metalloendopeptidase-like 1 (soluble form). Ch-450 targets 67\% proteases (alpha-trypsin chain 1, trypsin 2 and 3, activation peptide fragment 1 , urokinase-type plasminogen activator long chain A, tissue-type plasminogen activator, hepatocyte growth factor activator long chain, apolipoprotein-a), 7\% other enzymes (enzyme FAD-linked sulfhydryl oxidase ALR), 13\% transcription factors (oxysterols receptor LXR-alpha and beta) and 13\% unclassified proteins (plectin, microtubule-associated protein tau). Ch-458 can dominantly control serine proteases (73\%) including chymase, chymotrypsin- $C$, cathepsin G, Granzyme $\mathrm{B}$ and $\mathrm{H}$, chymotrypsin-like elastase family member $1,2 \mathrm{~A}, 2 \mathrm{~B}, 3 \mathrm{~A}$ and $3 \mathrm{~B}$ and neutrophil elastase as well as acetylcholinesterase, poly [ADP-ribose] polymerase 14 and microtubule-associated protein tau. Besides enzymes (74\%; telomerase reverse transcriptase, cathepsin G, monoglyceride lipase), Ch-459 can also interact with ion channels (13\%) like ATP-sensitive inward rectifier potassium channels 11,1 and 8 . It has been previously reported that some of these proteins are positive and negative regulators of cancer. For examples, microtubule-associated protein tau is associated with paclitaxel resistance in breast and gastric cancer patients [34, 35] and upregulated hepatocyte growth factor activator and trypsin like proteases in cancer tissues are involved with carcinogenesis and metastasis [36]. In contrast, muscleblind-like protein 1 is implicated in suppression of breast cancer metastatic colonization [37]; granzymes play key role in antitumor immunity [38] and FKBP1A is a target for anticancer drug rapamycin [39]. Predicted interaction of our compounds with previously reported proteins in cancer provides evidence for their beneficial role.

\section{Cytotoxicity of tributyltin (IV) compounds}

Cytotoxicity of tributyltin (IV) compounds was quantified against HepG2, THP-1 cell lines and isolated

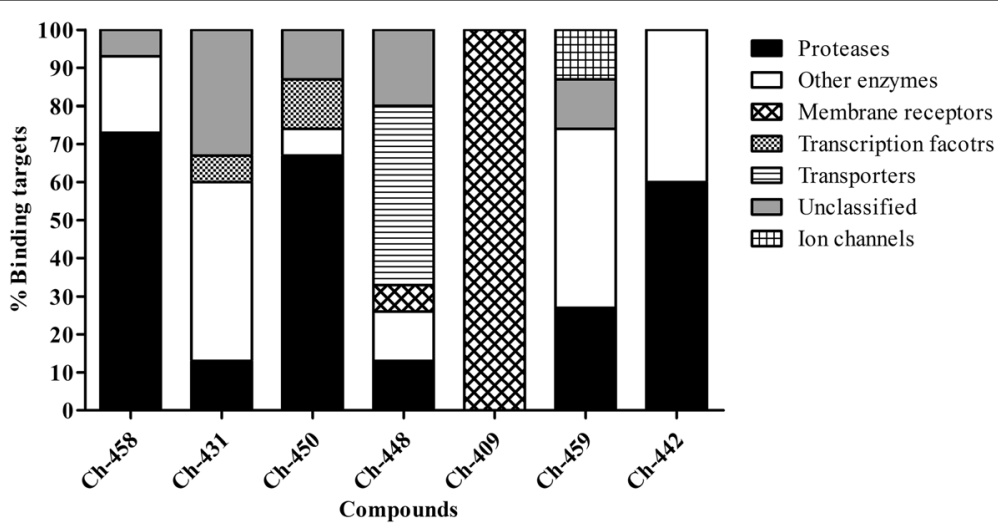

Fig. 4 Predicted molecular targets for tributyltin (IV) compounds. Molecular target prediction is done by SwissTargetPrediction tool. Each bar represents the targets for each compound based on structural homology and binding potential of similar compounds in database. Unclassified shows the proteins that are not classified into any group 
lymphocytes at $20 \mu \mathrm{g} / \mathrm{mL}$ to compare effect at same concentration (Table 2). All compounds showed significantly higher $(p<0.05)$ cytotoxicity against HepG2 cell line except Ch-442. Ch- 450 and Ch-459 exhibited significant cytotoxicity against THP-1 cells whereas activity of other compounds was lower than $50 \%$ at same concentration. On the contrary, Ch-409, Ch-459 and Ch-442 were toxic against normal isolated lymphocytes. However, IC50 values of these compounds for HepG2 cells were 10-100 times lower than those for isolated lymphocytes (Table 2). There was no significant cytotoxicity of other compounds against normal cells. This partially selective response against cancer cell lines is beneficial in targeting cancer cells whereas limiting damage to normal cells. Results are comparable with standard doxorubicin against HepG2 cells while lower in case of vincristine against THP-1 cells and lymphocytes. It can be seen that vincristine is significantly toxic against normal lymphocytes. Our compounds showed cytotoxicity against HepG2 cell line comparable to previously reported data on oxaliplatin and cisplatin [40]. On the contrary, lymphocyte cytotoxicity was more pronounced in carboplatin and cisplatin [23].

It was reported that carboxylate derivatives of organotin such as phenylacetate, benzoate and cinnamates were found effective against tumor cell lines. Some of the din-butyltin compounds were proved more potent than cisplatin [41]. In line with this, our results are comparable with previous study where different organotin (IV) carboxylate compounds revealed significant anticancer activity against kidney fibroblast (BHK-21) and lung carcinoma (H-157) cell lines [10]. This indicates prospective of tributyltin (IV) carboxylate compounds as potential candidates for anticancer drug development. Further screening of compounds used in present study is recommended against a range of cancer and normal cell lines to evaluate their efficacy and selectivity. Several reports presented that there is no well-defined mechanism by which organotin compounds can interact with cancer cells. Their intercalation with phosphodiester backbone of DNA is reported, altering intracellular breakdown of phospholipids of endoplasmic reticulum [42, 43]. Organotin compounds may also bind with membrane proteins, cellular kinases, ATPase or glycoproteins [44]. We have found these compounds as protein kinase inhibitors, which can be one of the mechanisms for cytotoxicity. However, detailed mechanism of action of these compounds is to be elucidated.

\section{Antileishmanial activity}

Tributyltin (IV) compounds demonstrated highly significant $(p<0.05)$ antileishmanial activity with $>90 \%$ lethality and very low LC50s ranging from $0.954 \pm 0.158 \mu \mathrm{g} / \mathrm{mL}$ to $0.078 \pm 0.002 \mu \mathrm{g} / \mathrm{mL}$ (Table 3). Lowest LC50 was observed by Ch- 431 that appears equipotent to the standard amphotericin B. It has been reported that sodium stibogluconate showed IC50s of $64 \mu \mathrm{g} / \mathrm{mL}$ and $22 \mu \mathrm{g} / \mathrm{mL}$ against axenic log-phase promastigotes and cellular metacyclic promastigotes respectively [45]. Our compounds appear to be more potent than sodium stibogluconate. Compounds were further tested for their photocatalytic activity by exposing to sunlight, sunlight with IR filter and dark conditions. There was $0-32 \%$ toxicity against leishmania when exposed to light and dark conditions without samples. Compounds showed no significant photosensitizing effect after normalizing the data indicating that their activity is independent of light conditions. Samples were further tested in the presence of ROS scavengers $\mathrm{NaN}_{3}$ and mannitol, which scavenge singlet oxygen [46] and hydroxyl radicals [47] respectively. ROS are important molecules in controlling leishmania infection that are generated by macrophages during phagocytosis of parasite [48]. It was observed that antileishmanial activity of compounds was reduced by $16.38 \%-34.38 \%$ in the presence of $\mathrm{NaN}_{3}$ whereas it was reduced by $15-38.2 \%$ in the presence of mannitol as compared with $16 \%$ and $10 \%$ decline for amphotericin $\mathrm{B}$ in the presence of $\mathrm{NaN}_{3}$ and mannitol respectively. Ch- 442 showed selective toxicity against leishmania with $95.8 \pm 1.16 \%$ lethality as compared with $12.8 \pm 0.37 \%$ and $44.6 \pm 0.18 \%$ cytotoxicity against HepG2 and THP-1 cells respectively. Moreover, antileishmanial L50 $(0.088 \pm 0.009 \mu \mathrm{g} / \mathrm{mL})$ is approximately 15 times lower than IC50 $(14.9 \pm 0.25 \mu \mathrm{g} / \mathrm{mL})$ against isolated lymphocytes. Activity of Ch- 442 was reduced by $22 \%$ and $38.2 \%$ in the presence of $\mathrm{NaN}_{3}$ and mannitol respectively. These results indicate that ROS production by compounds is one of the mechanisms for antileishmanial effect.

\section{Structure-activity relationship}

Tributylstannyl carboxylate is the primary moiety responsible for cytotoxicity of these compounds. We compared all compounds with $\mathrm{Ch}-458$, which has double bond at position 2, phenylamino ring and one tributylstannyl group with an IC50 of $1.58 \mu \mathrm{g} / \mathrm{mL}$ against HepG2 cells. Replacing the oxo-phenylaminobutanoic acid ligand with phenylenebis(oxy) diacetic acid has enhanced the potency of Ch-409 by 19-fold providing maximum cytotoxicity with lowest IC50 value. Dimethyl substitution at phenylamino ring in Ch-459 augmented its potency by 2.54 -fold compared to Ch- 458 . On the contrary, substitutions of naphthalene-1-ylcarbamoyl, ethoxycarbonyl at position 4 on phenylamino group and missing double bond at position 2 reduced potency of compounds Ch- 450 , Ch- 431 and Ch- 448 by $1.77,3.46$ and 2.18-folds respectively. However, presence of cyclohexyl ring instead of phenyl may have hindered binding 


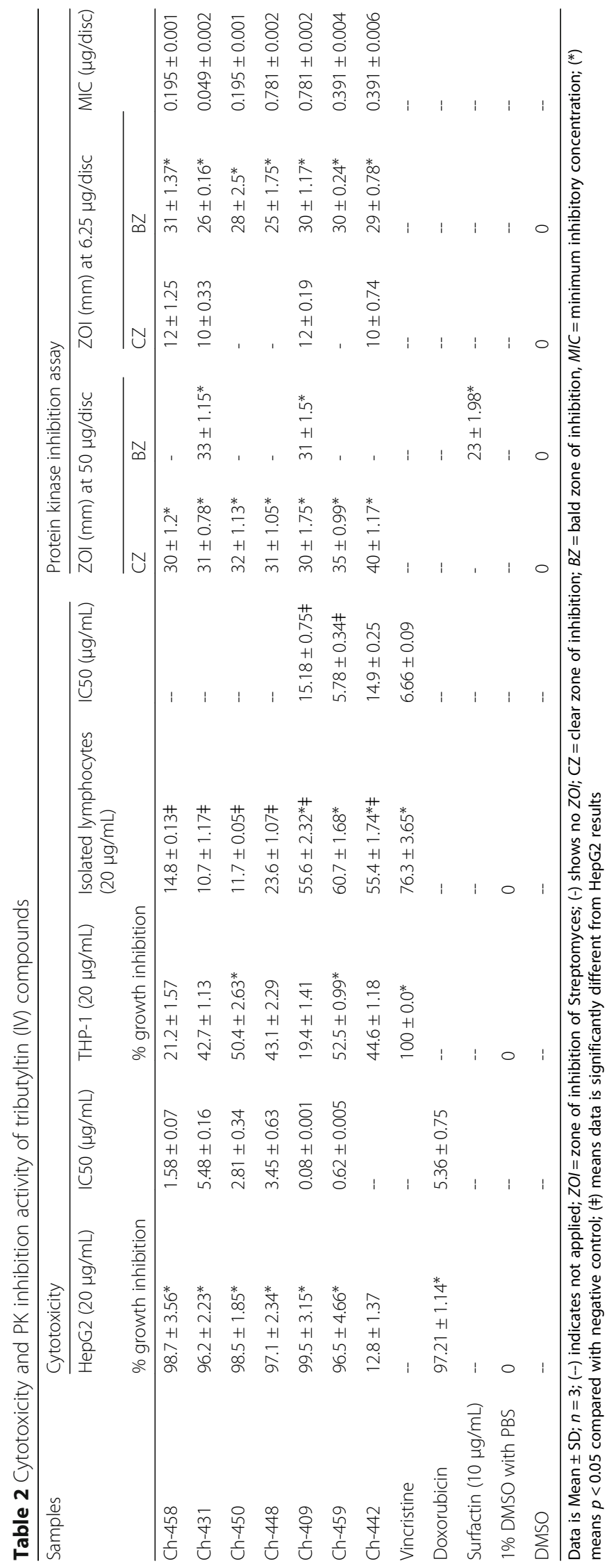




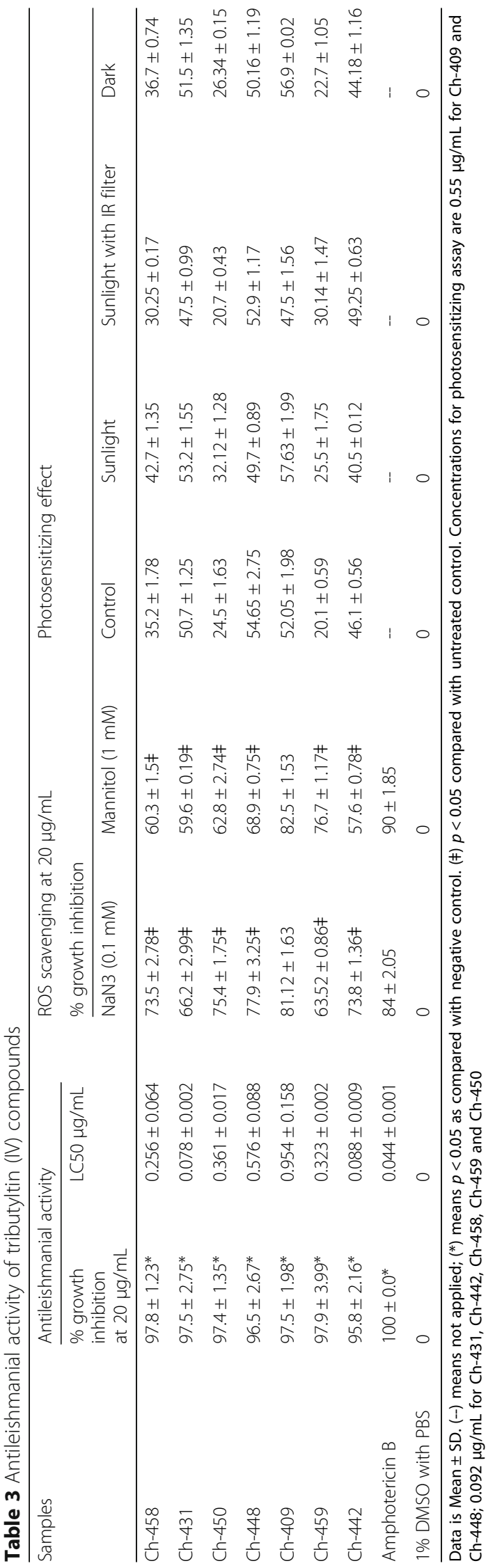


affinity of Ch-442 to target proteins in HepG2 cells causing no cytotoxicity.

In case of THP-1 cells, addition of naphthalene (Ch-450) and dimethylphenyl (Ch-459) might have enhanced binding of compounds to specific targets in THP1 cells that vary from HepG2 and isolated lymphocytes. Nevertheless, the cytotoxicity is only around $50 \%$ at concentration of $20 \mu \mathrm{g} / \mathrm{mL}$. Since, proteins and cellular components may vary between normal and cancer cells; therefore, activity of our compounds was pronounced against HepG2 cells with little/no effect against isolated lymphocytes. Substitutions of cyclohexyl ring (Ch-442), dimethylphenyl (Ch-459) and phenylenebis(oxy) diacetic acid (Ch-409) showed cytotoxicity against isolated lymphocytes. It is possible that these compounds gained access to biomarkers similar in normal and cancer cells. Since, Ch-459 showed cytotoxicity in all three cell types used; therefore, presence of dimethylphenyl group appears to be an important modulator of cytotoxicity.

Compounds were also highly cytotoxic against leishmania promastigotes. Ch-409 with phenylenebis(oxy) diacetic acid ligand was least potent among all compounds with LC50 $0.954 \mu \mathrm{g} / \mathrm{mL}$. Substitution of ethoxycarbonyl at position 4 on phenylamino group (Ch-431) gained maximum access to specific leishmania proteins and was 12.23-fold potent than Ch-409. Cyclohexyl moiety in Ch-442 showed targeted affinity for leishmania specific proteins or other biomolecules allowing selective cytotoxicity behavior with 10.84-fold higher potency than Ch-409 and 1.12-fold lower than Ch-431. Similarly, respective substitutions in Ch-458, Ch-459, Ch-450 and Ch-448 reduced potency by $3.28,4.14,4.62$ and 7.38folds compared with Ch-431. Reduction of a double bond at position 2 drastically decreased potency of Ch448. Thus, tributylstannyl carboxylate backbone is highly cytotoxic against leishmania promastigotes and ligand modifications on it caused potency variations. Our results indicate dissimilarity in compounds' behavior against cancer cells, normal cells and leishmania. It depicts that these have different molecular targets as well as variable affinity against same biomolecules. This is supported by our insilico molecular target prediction where both variable and overlapping interaction site have been predicted. Thus, these compounds have multimode cytotoxicity with potential for varied diseases.

\section{Protein kinase inhibition activity}

Protein kinases are essential modulators of cellular regulations and physiological processes [49]. Irregular activation of these kinases constitutes oncogenic signals. Cytoplasmic (Abl) or transmembrane (PDGFR, EGFR) protein kinases found in many cancer cells are targets for anticancer drugs to induce cytotoxicity [50]. Thus, we assessed inhibition of protein kinases as possible mechanism of cytotoxicity in our study.

Being highly cytotoxic, initially clear zones were observed; however, compounds provided bald zones at lower doses with no cytotoxicity. Bald zone specify protein kinase inhibition by obstructing aerial hyphae formation whereas clear zones indicate complete inhibition of Streptomyces growth. Lowest MIC for PK inhibition was shown by Ch-431 (Table 2). MIC for PK inhibition is much lower than IC50 for HepG2 cytotoxicity and is somewhat comparable with LC50 for antileishmanial activity. It means that these compounds are effective in targeting protein kinase enzymes and other associated factors at lower doses that those which cause cytotoxicity.

Molecular target prediction predicted enzymes as likely targets. Although, in-silico target prediction shows little data on binding probability with kinases; however, we experimentally proved this fact that tributyltin (IV) carboxylate compounds used in our study significantly inhibited $(p<0.001)$ protein kinase activity in Streptomyces. Streptomyces requires protein kinase activity of RamC to convert pre-Sap B to Sap B, a surfactant important for aerial hyphae formation [51]. It has been found that RamC is a membrane associated receptor kinase [51], which supports binding of all our compounds with this motif including Ch-409 whose major targets are predicted to be receptors only. This indicates significance of tributyltin (IV) compounds in protein kinase inhibition that may be a reason for cytotoxicity in cancer cells and leishmania. Oncogenesis is mediated either directly or indirectly by transmembrane or cytoplasmic tyrosine/serine-threonine kinases [52]. Furthermore, MAPK MAPK-like kinases, cyclin-dependent kinase (Cdk) and glycogen synthase kinase 3 are implicated in growth, differentiation and infectivity of leishmania parasite [53]. Thus, our data suggests molecular level studies to further explore exact mechanism of these compounds.

\section{Conclusions}

Tributyltin (IV) carboxylate compounds are contenders of anticancer and antileishmanial drug development. Insilico analysis shows these compounds partially druglike, permeable across GI membrane and blood brain barrier and mutagenic with possible risk of hERG inhibition. High PPB and rate of metabolism will provide very low free drug concentration in plasma that may reduce the risk of side effects, which can be further managed using targeted drug delivery system. Our new compounds are highly cytotoxic against HepG2 cells and leishmania parasite with lower cytotoxicity against normal isolated lymphocytes. These significantly inhibit 
protein kinase with very low IC50 values. These compounds can be evaluated further based on their risk benefit ratio.

\section{Abbreviations}

ADMET: Absorption, distribution, metabolism, elimination and toxicity; BZ: Bald zone; CZ: Clear zone; NOR: Normalized occurrence ration; ZOI: Zone of inhibition

\section{Acknowledgements \\ There are no acknowledgements in this manuscript.}

\section{Funding}

This research did not receive any specific grant from funding agencies in the public, commercial, or not-for-profit sectors. However, indigenous scholarship for PhD studies from Higher Education Commission, Pakistan is acknowledged.

\section{Availability of data and materials}

Not applicable.

\section{Authors' contributions}

DW performed the experiments and was the major contributor in writing the manuscript. IH has made substantial contribution to the concept and design of study. AFB synthesized and provided the compounds. MHB and GMK facilitated in in vitro evaluation, data analysis and critically reviewed the manuscript for important intellectual comments. All authors read and approved the final manuscript.

\section{Competing interests}

The authors declare that they have no competing interests.

\section{Consent for publication}

Not applicable.

\section{Ethics approval and consent to participate}

Ethical approval was taken from Bio-Ethical Committee of Quaid-i-Azam University, Islamabad, Pakistan to obtain blood samples from health volunteers for lymphocyte isolation (Reference No. BEC-FBS-QAU-92). The participants consented voluntarily to donate blood for the purpose of this study.

\section{Publisher's Note}

Springer Nature remains neutral with regard to jurisdictional claims in published maps and institutional affiliations.

\section{Author details}

'Department of Pharmacy, Quaid-i-Azam University, Islamabad 45320, Pakistan. ${ }^{2}$ Department of Chemistry, Allama labal Open University, $\mathrm{H}-8$, Islamabad 44000, Pakistan

Received: 15 January 2017 Accepted: 31 March 2017

Published online: 04 April 2017

\section{References}

1. Clem A. A current perspective on leishmaniasis. J Glob Infect Dis. 2010;2(2):124-6.

2. Gazdar AF, Miyajima K, Reddy J, Sathyanarayana UG, Shigematsu H, Suzuki M, et al. Molecular targets for cancer therapy and prevention. Chest J. 2004; 125(5_suppl):975-101S

3. Gross S, Rahal R, Stransky N, Lengauer C, Hoeflich KP. Targeting cancer with kinase inhibitors. J Clin Invest. 2015;125(5):1780-9.

4. Singh N, Kumar M, Singh RK. Leishmaniasis: current status of available drugs and new potential drug targets. Asian Pac J Trop Med. 2012;5(6):485-97.

5. Xingi E, Smirlis D, Myrianthopoulos V, Magiatis P, Grant KM, Meijer L, et al. 6Br-5methylindirubin-3' oxime (5-Me-6-BIO) targeting the leishmanial glycogen synthase kinase-3 (GSK-3) short form affects cell-cycle progression and induces apoptosis-like death: exploitation of GSK-3 for treating leishmaniasis. Int J Parasitol. 2009;39(12):1289-303.
6. Martins P, Marques M, Coito L, Pombeiro AJ, Baptista PV, Fernandes AR. Organometallic compounds in cancer therapy: Past lessons and future directions. Anticancer Agents Med Chem. 2014;14(9):1199-212.

7. Sánchez-Delgado RA, Anzellotti A, Suárez L. Metal complexes as chemotherapeutic agents against tropical diseases: malaria, trypanosomiasis, and leishmaniasis. Met lons Biol Syst. 2004:41:379-420.

8. Haldar AK, Sen P, Roy S. Use of antimony in the treatment of leishmaniasis: current status and future directions. Mol Biol Int. 2011;2011:1-23.

9. Dasari S, Tchounwou PB. Cisplatin in cancer therapy: molecular mechanisms of action. Eur J Pharmacol. 2014;740:364-78.

10. Sirajuddin M, Ali S, McKee V, Zaib S, lqbal J. Organotin (IV) carboxylate derivatives as a new addition to anticancer and antileishmanial agents: design, physicochemical characterization and interaction with Salmon sperm DNA. RSC Adv. 2014;4(101):57505-21.

11. Frézard F, Demicheli C, Ribeiro RR. Pentavalent antimonials: new perspectives for old drugs. Molecules. 2009;14(7):2317-36.

12. McWhinney SR, Goldberg RM, McLeod HL. Platinum neurotoxicity pharmacogenetics. Mol Cancer Ther. 2009;8(1):10-6.

13. Hong M, Yang Y, Li C, Xu L, Li D, Li C-z. Study of the effect of molecular structure and alkyl groups bound with tin (IV) on their cytotoxicity of organotin (IV) 2-phenyl-4-selenazole carboxylates. RSC Adv. 2015;5(124):102885-94.

14. Hussain S, Ali S, Shahzadi S, Sharma SK, Qanungo K, Shahid M. Synthesis, characterization, semiempirical and biological activities of organotin (IV) carboxylates with 4-piperidinecarboxylic acid. Bioinorg Chem Appl. 2014; 2014:959203.

15. Lee SK, Chang GS, Lee $\mathbb{H}$, Chung JE, Sung KY, No KT: The PreADMET: PCbased program for batch prediction of ADME properties. EuroQSAR. 2004:9: 5-10.

16. Online SMILES Translator and Structure File Generator. National Institute of Health, USA. https://cactus.nci.nih.gov/translate/. Accessed 16 June 2016.

17. Daina A, Michielin O, Zoete V. iLOGP: a simple, robust, and efficient description of n-octanol/water partition coefficient for drug design using the GB/SA approach. J Chem Inf Model. 2014;54(12):3284-301.

18. Daina A, Zoete V. A BOILED-Egg to predict gastrointestinal absorption and brain penetration of small molecules. ChemMedChem. 2016;11(11):1117-21.

19. Boyer S, Arnby CH, Carlsson L, Smith J, Stein V, Glen RC. Reaction site mapping of xenobiotic biotransformations. J Chem Inf Model. 2007:47(2):583-90

20. Boyer S, Zamora I. New methods in predictive metabolism. J Comput Aided Mol Des. 2002;16(5):403-13.

21. Gfeller D, Grosdidier A, Wirth M, Daina A, Michielin O, Zoete V. SwissTargetPrediction: a web server for target prediction of bioactive small molecules. Nucleic Acids Res. 2014;42(W1):W32-8.

22. Haq I-U, Ullah N, Bibi G, Kanwal S, Sheeraz Ahmad M, Mirza B. Antioxidant and cytotoxic activities and phytochemical analysis of euphorbia wallichii root extract and its fractions. Iran J Pharm Res. 2010;11(1):241-9.

23. Suman $G$, Jamil K. Application of human lymphocytes for evaluating toxicity of anti-cancer drugs. Int J Pharmacol. 2006:2(4):374-81.

24. Suman G, Naravaneni R, Jamil K. In vitro cytogenetic studies of cypermethrin on human lymphocyte. Indian J Exp Biol. 2006;44(3):233-9.

25. Mosmann T. Rapid colorimetric assay for cellular growth and survival: application to proliferation and cytotoxicity assays. J Immunol Methods. 1983;65(1-2):55-63

26. Yao L, Fiona S, Ten-Jin K, Christophe W. Antileishmanial assay and antimicrobial activity on crude extracts of Melodinus eugeniifolus barks and leaves from Malaysia. Pharmacol Pharm. 2014;5:747-54.

27. Nadhman A, Nazir S, Khan MI, Arooj S, Bakhtiar M, Shahnaz G, et al. PEGylated silver doped zinc oxide nanoparticles as novel photosensitizers for photodynamic therapy against Leishmania. Free Radic Biol Med. 2014:77:230-8.

28. Fatima H, Khan K, Zia M, Ur-Rehman T, Mirza B, Haq I-U. Extraction optimization of medicinally important metabolites from Datura innoxia Mill.: an in vitro biological and phytochemical investigation. BMC Complement Altern Med. 2015;15(1):376

29. Vistoli G, Pedretti A, Testa B. Assessing drug-likeness-what are we missing? Drug Discov Today. 2008;13(7):285-94.

30. Lalitha P, Sivakamasundari S. Calculation of molecular lipophilicity and drug likeness for few heterocycles. Orient J Chem. 2010;26(1):135-41.

31. Ramakrishnan P. The role of P-glycoprotein in the blood-brain barrier. Einstein Q J Biol Med. 2003;19(1):160-5. 
32. van Noord C, Sturkenboom MC, Straus SM, Witteman JC, Stricker BHC. Noncardiovascular drugs that inhibit hERG-encoded potassium channels and risk of sudden cardiac death. Heart. 2011;97(3):215-20.

33. Iyanagi T. Molecular mechanism of phase I and phase II drug-metabolizing enzymes: implications for detoxification. Int Rev Cytol. 2007;260:35-112.

34. Mimori K, Sadanaga N, Yoshikawa Y, Ishikawa K, Hashimoto M, Tanaka F, et al. Reduced tau expression in gastric cancer can identify candidates for successful Paclitaxel treatment. Br J Cancer. 2006;94(12):1894-7.

35. Rouzier R, Rajan R, Wagner P, Hess KR, Gold DL, Stec J, et al. Microtubuleassociated protein tau: a marker of paclitaxel sensitivity in breast cancer. Proc Natl Acad Sci USA. 2005;102(23):8315-20.

36. Kawaguchi M, Kataoka H. Mechanisms of hepatocyte growth factor activation in cancer tissues. Cancers. 2014;6(4):1890-904.

37. Fish L, Pencheva N, Goodarzi H, Tran H, Yoshida M, Tavazoie SF. Muscleblind-like 1 suppresses breast cancer metastatic colonization and stabilizes metastasis suppressor transcripts. Genes Dev. 2016;30(4):386-98.

38. Cullen S, Brunet M, Martin S. Granzymes in cancer and immunity. Cell Death Differ. 2010;17(4):616-23.

39. Zhou XZ, Lu KP. The isomerase PIN1 controls numerous cancer-driving pathways and is a unique drug target. Nat Rev Cancer. 2016;16:463-78.

40. Pascale F, Bedouet L, Baylatry M, Namur J, Laurent A. Comparative chemosensitivity of VX2 and HCC cell lines to drugs used in TACE. Anticancer Res. 2015;35(12):6497-503.

41. Xiao X, Liang C, Zhao W. Organotin carboxylates: from structures to antitumour activities. Eur J BioMed Res. 2015;1(4):23-7.

42. Li Q, Yang P, Wang H, Guo M. Diorganotin (IV) antitumor agent. (C 2 H 5) 2 $\mathrm{SnCl} 2$ (phen)/nucleotides aqueous and solid-state coordination chemistry and its DNA binding studies. J Inorg Biochem. 1996;64(3):181-95.

43. Pellerito L, Nagy L. Organotin (IV) ${ }^{\text {n+ }}$ complexes formed with biologically active ligands: equilibrium and structural studies, and some biological aspects. Coord Chem Rev. 2002;224(1):111-50.

44. Rocamora-Reverte L, Carrasco-García E, Ceballos-Torres J, Prashar S, Kaluđerović GN, Ferragut JA, et al. Study of the anticancer properties of tin (IV) carboxylate complexes on a panel of human tumor cell lines. ChemMedChem. 2012;7(2):301-10.

45. Vermeersch M, da Luz RI, Toté K, Timmermans J-P, Cos P, Maes L. In vitro susceptibilities of Leishmania donovani promastigote and amastigote stages to antileishmanial reference drugs: practical relevance of stage-specific differences. Antimicrob Agents Chemother. 2009;53(9):3855-9.

46. Bancirova M. Sodium azide as a specific quencher of singlet oxygen during chemiluminescent detection by luminol and Cypridina luciferin analogues. Luminescence. 2011;26(6):685-8.

47. Desesso JM, Scialli AR, Goeringer GC. D-mannitol, a specific hydroxyl free radical scavenger, reduces the developmental toxicity of hydroxyurea in rabbits. Teratology. 1994;49(4):248-59.

48. Carneiro PP, Conceição J, Macedo M, Magalhães V, Carvalho EM, Bacellar O. The role of nitric oxide and reactive oxygen species in the killing of leishmania braziliensis by monocytes from patients with cutaneous leishmaniasis. PloS One. 2016;11(2):e0148084.

49. Cheng H-C, Qi RZ, Paudel H, Zhu H-J. Regulation and function of protein kinases and phosphatases. Enzyme Res. 2011;2011:1-3.

50. Tsatsanis C, Spandidos DA. The role of oncogenic kinases in human cancer (Review). Int J Mol Med. 2000;5:583-90.

51. Hudson ME, Zhang D, Nodwell JR. Membrane association and kinase-like motifs of the RamC protein of Streptomyces coelicolor. J Bacteriol. 2002;184(17):4920-4

52. Tsatsanis, Christos, Zafiropoulos, Alexandros, and Spandidos, Demetrios A. Oncogenic Kinases in Cancer. In: eLS. John Wiley \& Sons Ltd, Chichester. 2007. http://www.els.net. [doi: 10.1002/9780470015902.a0006051.pub2].

53. Morales MA, Pescher P, Späth GF. Leishmania major MPK7 protein kinase activity inhibits intracellular growth of the pathogenic amastigote stage. Eukaryot Cell. 2010;9(1):22-30.

\section{Submit your next manuscript to BioMed Central and we will help you at every step:}

- We accept pre-submission inquiries

- Our selector tool helps you to find the most relevant journal

- We provide round the clock customer support

- Convenient online submission

- Thorough peer review

- Inclusion in PubMed and all major indexing services

- Maximum visibility for your research

Submit your manuscript at www.biomedcentral.com/submit
) Biomed Central 